\title{
Sağlık Kurumlarında Risk Yönetimi
}

\author{
Risk Management in Health Institutions
}

\author{
Nesrin ÖZCAN
}

ÖZ

Sağlık kurumlarında risk yönetimi; sağlık hizmetinin ve işletmenin varlığının devamlılığının sağlanmasında mevcut risklerin başarıyla tanınması, yönetilmesi ve azaltılmasıdır. Stratejik kararlarda belirsizliklerin, risklerin ve firsatların kurumun iş başarısı için bir araç olarak kullanılabilmesidir. Sürecin etkin yönetilebilmesi için tüm pozisyonlara ait görev, yetki ve sorumluluklar net bir şekilde belirlenerek çalışanlara bildirilmelidir ve çalışanlar da üzerlerine düşen sorumlulukları yerine getirmelidir. Başarılı bir risk yönetimi programı tüm çalışanların risk yönetimi felsefesini anlayarak uygulaması ile mümkün olur.

Risklerin yönetilebilmesi için belli özelliklerine göre sınıflandırılması gerekmektedir. Çeşitli kurum ve kuruluşlar tarafından sağlık kuruluşları için oluşturulmuş taksonomiler mevcuttur, kurumlar kendi yapılarına uygun sistemler de geliştirebilirler.

Bir kurumun risk yönetimi süreçleri, piyasadaki rekabetin niteliğine ve rakiplerinin risk yönetimi süreçlerine bağlıdır. Tüm kurumlarda işe yarayacak ortak bir risk çözüm yöntemi yoktur, her kurumun sahip olduğu riskler farklı olduğu gibi bu risklerle başa çıkma yöntemleri de farklıdır. Risk yöneticileri kurumun risk dağılımını anlamalı ve olasılıklara karşı kurumu yönetmek yerine gelecekteki olasılıkları yönetecek düşünceler geliştirmeli ve hareket etmelidir. Ancak o zaman stratejik planlama ve risk yönetimi tamamlayıcı süreçler haline gelir.

$\mathrm{Bu}$ çalışma sağlık kurumlarında risk yönetiminin amaçlarını ve kurum içerisinde görev dağılımlarını anlamak, risk yönetiminin sağlık kurumlarında uygulanan standartlardaki yerini açıklamak ve sağlık kurumlarında uygulanabilecek bir örnek sunmak amacı ile oluşturulmuştur.

Anahtar Kelimeler: Sağlıkta risk yönetimi, risk analizi, risk değerlendirme, risk yönetim planı

\begin{abstract}
Risk management in health institutions is the successful identification, management and reduction of existing risks in ensuring the continuity of the health service and the enterprise. It is the use of uncertainties, risks and opportunities for strategic decisions used as a tool for the institution. In order to be able to effectively manage the process; the duties, authorities and responsibilities of all positions must be clearly defined and reported to the employees, and the employees must fulfill their responsibilities. The risk management philosophy's being understood by all employees is necessary for a successful risk management program.

Risks need to be classified according to their specific characteristics in order to be managed. There are taxonomies established by various institutions and organizations for health institutions, and institutions can develop systems that are appropriate for their own structures.

Risk management processes of an institution depend on the nature of the competition in the market and the risk management processes of its competitors. There is no common risk solution method that will work for all institutions; as the risks that each institution has are different, the ways of coping with these risks will also differ. For this reason, risk managers should understand the risk distribution of the firm and should develop and act on behaviors that will govern future possibilities rather than managing the institution against likelihoods. Only then strategic planning and risk management become complementary processes.

This study aims to understand the aims of risk management in health institutions and the distribution of tasks within the organization, to explain the place of risk management in the standards implemented in health institutions and to give an example that can be applied in health institutions.
\end{abstract}

Keywords: Health risk management, risk analysis, risk assessment, risk management plan 


\section{GİRiş}

Sağlık kurumlarında risk yönetimi son yıllarda sıkça konuşulmaya başlanmış, Risk Yönetim Planlarının nasıl yapılacağı sağlı yöneticilerinin düşündükleri ve araştırdıkları bir konu haline gelmiştir. İş Sağlığ 1 ve Güvenliği kapsamında sağlık kuruluşlarında risk planları yapılmaya başlanmıştır. Ancak risk yönetiminin organizasyonun tüm süreçlerini kapsayacak şekilde ele alınması ile ilgili gelişme henüz gösterilememiştir. Sağlık Kurumları için risk yönetimi aslında yeni bir kavram değildir; uzun zamandır dağınık şekilde gerçekleştirilen risk yönetim faaliyetlerinin bir araya toplanıp bütüncül bir şekilde sistem yaklaşımı ile ele alınmasıdır.

Sağlık kurumlarında birçok konuda riskler çok uzun yıllardır yönetilmektedir. Örneğin; laboratuvarlarda gerçekleştirilen günlük kalibrasyon, kalite kontrol faaliyetleri hatalı sonuçların çıkmasını engellemek üzere yapılan bir risk yönetimi faaliyetidir.

Kliniklerde defibrilatörün her nöbet tesliminde çalışıp çalışmadığını kontrol etmek, görünüşü benzeyen ilaçları aynı rafta tutmamak, ameliyata alınacak hastaya bir dizi tetkik yapmak, çalışanlara kişisel koruyucu ekipman temin edip kullanmalarını sağlamak özüne bakıldığında risk yönetmek üzere gerçekleştirilen sayısız faaliyete verilecek örneklerdir.

Sağlik kurumlarında risk yönetimi düşünüldüğünde merkezde her zaman hasta güvenliği ve çalışan güvenliği olmak zorundadır. Ancak sağlık kurumlarının da bir işletme olduğunu ve finansal, stratejik ve operasyonel süreçlerinin kontrol altında olması gerektiğini unutmamak gerekir. İyi yönetilen veri raporlama sistemleri ile tüm süreçlerin sistem yaklaşımıyla ele alınıp mevcut risklerin tanımlanması, değerlendirilmesi ve kontrol altına alınması gerekmektedir. $\mathrm{Bu}$ makale sağlık kurumlarında risk yönetimini tüm boyutları ile ele alıp, sağlık yöneticilerine örnek oluşturabilecek bir risk yönetim planını paylaşmayı amaçlamaktadır.

\section{Risk Yönetimi}

Sağlık kurumlarında risk yönetimi sağlık hizmetinin ve işletmenin varlığının devamlılı̆̆ın sağlanmasında mevcut risklerin başarıyla tanınması, yönetilmesi ve azaltılmasıdır. Stratejik kararlarda belirsizliklerin, risklerin ve firsatların kurumun iş başarısı için bir araç olarak kullanılabilmesidir.

Risk Yönetimi International Organization for Standardization (ISO) 31000:2009 Risk Yönetimi
Standardında risk yönetiminin organizasyonel süreçlerin ayrılmaz bir parçası olduğunu; süreç yönetimi, değişim yönetimi ve stratejik yönetimi içinde barındıran yönetimin sorumluluğu altında organizasyonel bir süreç olduğunu belirtmektedir (1).

Genel anlamda, risk yönetimi, bir kuruluşta veya kurumda varlıkları korumak ve finansal kayıplarını en aza indirgemek için yapılan işlemdir. Kurumsal Risk Yönetimi, kuruluşların sistematik düşünmelerini ve işlevsel siloları ortadan kaldırmalarını gerektirir (2).

Carroll'a göre sağlıkta risk yönetimi; bakımın her aşamasındaki risklerin sinerjik etkisinin tanınması, belirsizliklerin ve değişkenliğin azaltılması, hastanın güvenliğinin arttırılması; kurumun varlığını koruma, değer yaratma yoluyla yatırımın geri dönüşünün en üst düzeye çıkarılmasında yardımcı bir süreçtir (3).

Risk yönetiminde iki kavramı anlamak gerekir: Tehlike: Potansiyel zarar kaynağı olarak tarif edilir.

Risk: Belirsizliğin hedefler üzerinde yarattığı etkidir.

Risk ihtimali ve sonuçları doğal veya artık değer olarak değerlendirilebilir. Yapısal (Doğal) risk, bir organizasyonun sahip olduğu hafifletici kontrollerin hiçbirine bakılmaksızın değerlendirilir. Artık risk, mevcut kontrol mekanizmaları ile bağlantılı olarak riski göz önünde bulundurur. Kontrol değerlendirmesi, hangi kontrollerin mevcut olduğunu ve tespit edilen riskleri yönetmek için ne kadar etkili olduklarını inceler (4).

Risk yönetimi süreci objektif-kanıta dayalı, verimli ve pragmatik bir şekilde yürütülmelidir. Riskleri değerlendirmede kullanılan verilerin bilimsel yöntemlere ve kanıta dayalı güvenilir olması gerekir. Etkin bir risk yönetimi programının arkasında iyi bir veri havuzu bulunur. Risklerin önceliklendirilmesi, azaltılması ve yok edilmesinde kullanılacak kurum kaynaklarının maksimum faydayı sağlayacak ve hedeflere ulaştıracak şekilde dağıtılması önemlidir (5).

\section{Stratejik Risk Yönetimi}

Bir kurumun risk yönetimi süreçleri, piyasadaki rekabetin niteliğine ve rakiplerinin risk yönetimi süreçlerine bağlıdır. Tüm kurumlarda işe yaracak ortak bir risk çözüm yöntemi yoktur, her kurumun sahip olduğu riskler farklı olduğu gibi bu risklerle başa çıkma yöntemleri de farklıdır. $\mathrm{Bu}$ nedenle, risk yöneticileri kurumun risk dağılımını anlamalı 
ve olasılıklara karşı kurumu yönetmek yerine gelecekteki olasılıkları yönetecek düşünceler geliştirmeli ve hareket etmelidir. Ancak o zaman, stratejik planlama ve risk yönetimi tamamlayıcı süreçler haline gelir (6).

Başarılı bir risk yönetimi süreci için kurumun SWOT Analizinin etkili bir şekilde yapılmış olması ve stratejik hedeflerin mevcut riskleri ve bu risklerin değerlendirmelerini hesaba katarak belirlenerek tüm çalışanlara benimsetilmiş olmasi gerekmektedir.

Açıkça belirtilmiş hedefler olmadan, risk önceliklerini belirlemek için risk yönetimi programı başlatan bir kurumun bu süreci başarılı şekilde yönetmesi mümkün değildir (7).

\section{Sağlık Kurumlarında Risk Yönetiminin Amacı}

Sağlık kurumlarında risk yönetiminin amaçları aşağıda belirtilmiştir $(8,9)$;

- Hastaları, hastane personelini ve hastaneye gelen ziyaretçileri fiziki ve psikolojik bakımdan olumlu etkileyecek bir ortam yaratmak

- Kazaları önleme yönünde her türlü tedbiri almak ve bu tedbirleri alırken hastane kayıplarını ve harcamalarını minimize etmek

- Yaralanma hatta ölümle sonuçlanabilecek kazalara imkan vermeyerek tazminat giderlerini asgariye indirmek

- Kurumun varlığını devam ettirmesini tehdit eden finansal riskleri belirleyip önlem almak

- Yasal düzenlemelere uyumu hızlı bir şekilde sağlamak

- Mevcut riskleri ve firsatları kurumun fayda sağlayacağı sonuçlara yöneltmek

\section{Risk Yönetiminde Sorumluluklar}

Kurumsal risk yönetimi programı tüm çalışanların risk yönetimi felsefesini anlayarak uygulaması ile mümkün olur. Sürecin etkin yönetilebilmesi için tüm pozisyonlara ait görev, yetki ve sorumluluklar net bir şekilde belirlenerek çalışanlara bildirilmelidir ve çalışanlar da üzerlerine düşen sorumlulukları yerine getirmelidir. Ancak bazı pozisyonların risk yönetimi ile ilgili spesifik görevleri vardır (10):

\section{1. Üst Yönetim}

Risk yönetimi, hem reaktif hem de proaktif bir işlevdir. Beklenmedik olayların sıklığını ve şiddetini azaltmak, mevzuattaki değişikliklerin etkisini azaltmak ve yüksek güvenilirlik sağlamak üst yönetimin sorumluluğudur (11). Üst yönetim her türlü stratejik kararında risk yönetim planına göre hareket etmelidir (12). Bütüncül bir risk yönetim sürecine geçiş bir değişim süreci olduğundan risk yönetim komitesi ve risk yöneticisinin üst yönetimin desteğini alarak, kurumun vizyon, misyon ve hedefleri ile tutarlı planlamalar yapması sürecin başarısında kritik öneme sahiptir (13).

\subsection{Risk Yönetim Komitesi}

Sağlık kurumunun büyüklüğüne, hizmet çeşitliliğine, karmaşıklığına ve organizasyonel yapısına göre Risk Yönetimi Komitesi'nin yapısı ve üyeleri belirlenmelidir. Çok büyük ve karmaşık kuruluşlarda üst yönetimden oluşan Risk Yönetim Komitesi'nin üzerinde risk yönetim stratejilerini belirleyen ayrıca bir organ da bulunabilmektedir (14). Ülkemizdeki kurumları göz önünde bulundurduğumuzda; Risk Yönetimi Komitesi'nde Genel Müdür, Medikal Direktör, İdari Direktör, Mali Direktör, Kalite Yöneticisi, Hemşirelik Hizmetleri Müdürü gibi operasyonel yöneticiler, kurumda oluşturulmuş komitelerin başkanları ve birim yöneticileri mutlaka yer almalıdır. Risk Yönetim Komitesi kurumdaki tüm risklerin belirlenmesinde yönlendirici olur, süreçlerdeki risklerin birbirlerine etkilerinin ortaya konulmasında ve kurum içinde bulunan çalışanların mevcut risklerle ilgili görüşlerinin bir araya getirilmesinde rol oynar. Kısaca kurumun karş1 karşıya olduğu risklerin multidisipliner bakış açısıyla değerlendirilmesini sağlar. Risklerin değerlendirilmesi ve riskle başa çıkma yöntemlerine karar verilmesi noktasında üst yönetime öneriler sunar.

\subsection{Risk Yöneticisi}

Risk yöneticisi bu sürecin çatısını oluşturan merkezdeki pozisyondur. Sürecin başarısında rolü çok önemlidir ve seçilirken durumun hassasiyeti göz önünde bulundurularak tecrübeli, donanımlı, kurumu tanıyan, kurum çalışanları tarafından kabul gören ve değişimi başarıyla yönetilebilecek yöneticilere bu sorumluluğun verilmesi gerekmektedir. Yönetimsel gelişmelerle birlikte kurumsal çapta bir bakış açısıyla firsatlar ve riskler üzerine 
odaklanarak risk yöneticileri çok daha stratejik bir konuma sahip olacaktır (15).

Ülkemizde risk yönetimi süreçlerini daha çok Kalite Yöneticilerinin üstlendiğini görmekle birlikte sağlık kurumu büyüdükçe ve karmaşıklaştıkça sürecin önemi arttığından bu alanda uzmanlaşmış ve tüm ilgisini ve enerjisini bu sürece yöneltecek yöneticilerin görevlendirilmelerine ihtiyaç duyulmaktadır.

Kurumsal Risk Yönetim modelinde, Risk Yöneticisi üst yönetim ekibinin tüm üyelerine sınırsız erişime sahip olmalı, tüm komitelerin ve birimlerin çalışmalarını inceleyebilmeli, finansal ve operasyonel verilere ulaşabilmeli ve süreçlerle ile ilgili zor soruları sorabilmelidir. Üst yönetimin desteği ile kurumun karşı karşıya olduğu tüm riskler arasında bağlantı kurarak, tüm operasyonel yöneticiler ve süreç yöneticileri ile iş birliği içinde risklerin organizasyon çapında yönetilebilmesi için politikalar ve prosedürler tasarlamalı ve yönetmelidir (16).

Risk yöneticisinin temel görevleri aşağıdaki gibidir (16):

- Risk yönetimi komitesine başkanlık eder.

- Kuruluşun risk yönetimi faaliyetleri için bir çerçeve geliştirir.

- Kuruluşun düzenlemelere tam uyum sağlamasını sağlar.

- Politika değerlendirmeleri yapar.

- Risk değerlendirmesi, planlama, finansman ve risk transferi yoluyla iş sürekliliğini (felaket durumunda operasyonları sürdürme becerisi) temin eder.

- Acil riskleri tanımlar ve izler.

- Risk ilkelerini iş stratejilerine ve süreçlere adapte eder, risk yönetimi kültürünün oluşmasını sağlar.

- Operasyonel riskin doğru bir resmini oluşturmak için gereken veri stratejisini geliştirir, tanımlamak ve ölçmek için modeller kullanır.

- Risk Yönetim Komitesi'ne ve Yönetim Kurulu'na önemli risk konularını bildirir.

- Kurum genelinde entegre bir risk haritası geliştirir.

- Kuruluşun risk toleransını belirler.

- Sigorta kapsamını değerlendirir.

- Alternatif risk stratejileri geliştirir.

- Risk yönetimi politikaları ve yapıları hakkında çalışanlara ilgili eğitimler verir ve iletişim kurar.

\subsection{Birim ve Süreç Yöneticileri}

Birim ve süreç yöneticileri kendi sorumluluk alanlarındaki riskleri belirleyip Risk Yöneticisi'ne ve Risk Yönetim Komitesi'ne bildirerek aksiyon planlarının oluşturulmasında aktif rol oynamalı, diğer süreçlerle risk etkileşimlerini değerlendirmeli, organizasyonel risklerin farkında olup birimlerine yansımaları ile ilgili süreleri yönetmelidir.

\section{Sağlık Kurumlarında Risk Alanları}

Sağlık kurumunun yapısına göre risk alanları artırılıp azaltılabilir ancak genel olarak bir sağlık kurumundaki risk alanları aşağıdaki gibi belirlenebilir $(17,18)$ :

- Stratejik riskler

- Operasyonel riskler

- Klinik/ Hasta güvenliği ile ilgili riskler

- Finansal Riskler

- İnsan Kaynakları ile ilgili riskler

- Yasal riskler

- Teknolojik riskler

- Teknik, yapısal riskler

- Diğer riskler

\section{Risk Yönetimi Aşamaları}

Risk yönetimi sürecini iyi yönetebilmek için idari işbirliği gereklidir, çünkü bu tür değişiklikler zaman, insan gücü ve finansal kaynaklara önemli ölçüde bağlllık gerektirir. Üst yönetim ve kurumdaki liderler örgütsel kültürün oluşumunda önemli etkiye sahiptirler ve yöneticilerin risk yönetimi ile ilgili tutum ve destekleri, risk yönetimi kültürünün oturmasında temel oluşturmaktadır (19). Her aşamada başarıyı yakalayabilmek için tüm çalışanların risk yönetimi konusunda iyi bir eğitim almış ve sürecin felsefesini anlamış olması gerekmektedir. Risk yönetimi sürecinin aşamaları (20);

1. Kayıpların tanımlanması ve analizi,

2. Risk yönetimi tekniklerinin değerlendirilmesi, kurumun işleyişine ve yapısına uygun olan teknik ya da tekniklerin seçimi

3. Seçilen tekniklerin uygulanması,

4. Risk yönetimi programının sürekli izlenmesi ve iyileştirilmesi. 


\section{Sağlıkta Risk Yönetimi Taksonomileri}

Risklerin yönetilebilmesi için belli özelliklerine göre sınıflandırılması gerekmektedir. Çeşitli kurum ve kuruluşlar tarafindan sağlık kuruluşları için oluşturulmuş taksonomiler mevcuttur, kurumlar kendi yapilarına uygun sistemler de geliştirebilirler. Risk yönetimi taksonomilerine örnekler (21):

\section{- Hasta Güvenliği Olay Taksonomisi (PSET) :}

2005 yılında, sağlık kalitesi ölçüm ve raporlamaya yönelik ulusal bir strateji geliştirmek ve uygulamak için Joint Commission International (JCI) tarafından oluşturulan bir taksonomidir.

\section{- Sağlık Seviyesi 7 (HL7) - Hasta Güvenliği Grubu}

Sağlık Seviyesi 7 (HL7), görevi "klinik hasta bakımı ve sağlık hizmetlerinin yönetimini destekleyen verilerin değiş tokuşu, yönetimi ve entegrasyonu" için standartlar sunmak olan gönüllü ve kar amacı gütmeyen bir kuruluştur. HL7 Hasta Güvenliği İlgi Grubu halen, bakım noktası veri sistemleri, işlem sistemleri ve güvenlik raporu veri havuzları arasında birlikte çalışabilirliğin omurgasını oluşturacak Bireysel Durum Güvenliği Raporunu geliştirmektedir. HL7, sağlık alanında faaliyet gösteren birkaç Amerikan Ulusal Standart Enstitüsü (ANSI) tarafından akredite edilmiş Standards Developing Organizations (SDO)'dan biridir. HL7'nin alanı, klinik ve idari verilerdir.

\section{- Dünya Sağlık Örgütü (WHO) Hasta Güvenliği Taksonomisi}

Dünya Sağlık Örgütü, kilit hasta güvenlik terimleri ve kavramları için uluslararası kabul edilebilir bir terminoloji geliştirmektedir. Hasta güvenliğinin spesifik yönlerini iyileştirmek için "kilit eylem alanları" tanımlamıştır ve "ülkeler arasında ve dünyada sağlık bakımının daha güvenli hale getirilmesine yardımcı olmak için kaynaklar yaratılması" amaçlanmaktadır.

\section{- Tibbi Olay Bildirim Sistemleri}

Tıbbi olay taksonomileri üzerine yerel, ulusal ve uluslararası çalışmalara ek olarak, organizasyona bağlı olarak kullanılabilen çözümler bulunmaktadır.

\section{- Ulusal, Yerel Taksonomiler}

Ulusal veya hatta uluslararası kuruluşlar tarafindan oluşturulan sistemlerdir. Bu sinıflandırmaların amacı değişir; ancak genellikle karşılaştırma analizi, trend tanımlama ve analiz, performans geliştirme ve araştırmayı destekleyen veri yakalama ve raporlama yapılmasına olanak tanir.

\section{• Kuruma Özgü Taksonomiler}

Kuruma özgü olarak geliştirilen taksonomiler; tıbbi etkinlik bilgilerini toplamak ve kalite ve performans iyileştirme girişimlerini kolaylaştırmak için sağlık kuruluşları tarafından kendi yapılarına göre oluşturulmaktadır.

\section{Risk Yönetiminde Veri Raporlamanın Önemi}

Olay bildirme risk yönetiminin ayrılmaz bir parçasıdır. Olumsuz olayların raporlanması üzerine yapılan araştırmalar sağlık uzmanlarının özellikle de hekimlerin olayları üstlerine rapor etmeye gönülsüz olduğunu göstermektedir. Sonuçlar sağlık uzmanlarının işler ters gittiğinde olayı bir meslektaşına anlatma ihtimalinin en yüksek olduğunu göstermektedir (22).

Riskin değerini belirlerken görülme sıklığı puana etki eden unsurlardan biri olarak karşımıza çıkmaktadır. Bu sebeple risklerin değerin doğru belirlenmesi olayların etkin, açık ve eksiksiz bir şekilde raporlanmasına bağlıdır. Kurumlarda olay raporlama ile ilgili kültürün oturmuş olması risk yönetim sürecinde yüksek öneme sahiptir.

\section{Risk Yönetiminde Kullanılabilen Teknikler}

Risk yönetiminde kalite araçlarının birçoğunun kullanılabildiği görülmektedir. Örnek olabilecek bazı teknikler şunlardır (23):

- Hata Türü Etki Analizi( FMEA)

- 6 sigma

- Kalite Çemberleri

- İstatistiksel Proses Kontrolü (SPC) Neden Sonuç Analizi

- Sifir Hata Programı (ZFP)

- Pareto Analizi, Balık kılçığı vb. sorun belirleme yaklaşımları 


\section{Risk Yönetimi ve ISO 31000}

ISO 31000 Risk Yönetim Sistemi, kurumun faaliyet gösterdiği sektör ve büyüklügü gibi faktörlere bakılmaksızın etkin bir risk yönetimi için uygulanması gereken şartları tanımlayan ISO tarafından oluşturulmuş standarttır (24).

$\mathrm{Bu}$ standart kuruluşların genel idaresi, stratejisi ve planlaması, yönetimi, rapor verme süreçleri, politikaları, değerleri ve kültürü doğrultusunda risk yönetimi ile ilgili süreci bütünleştirmek amaçlı bir çerçeve geliştirmesini, uygulamasını ve sürekli olarak iyileştirmesini tavsiye eder (25).

ISO 31000: 2009 Riski yönetmek için prensipleri ve genel çatının oluşturulmasını kapsar.

Her sektör, faaliyet ve büyüklükteki firmaya uygulanabilir.

Belgelendirme amacı ile kullanılmaz, dış denetimlerle etkili yönetim tekniklerini kıyaslamak ve işbirliği sağlama amacı güder (26).

\section{Risk Yönetimi ve JCI}

Kurumsal Risk Yönetimi ile ilgili bir standardı bulunmamakla birlikte hasta güvenliği, bilgi yönetimi, tesis yönetimi gibi alanlarda risklerin sorgulanması ve gerekli önlemlerin alınması yönünde yönlendirmelerde bulunur (27).

2005 yılında sağlı kalitesi ölçüm ve raporlamaya yönelik ulusal bir strateji geliştirmek ve uygulamak için risk yönetiminin ayrılmaz bir parçası olan olay bildirimlerine yönelik Hasta Güvenliği Olay Taksonomisi (PSET) JCI tarafindan oluşturulmuştur.

\section{Risk Yönetimi ve ISO 9001}

ISO 9001 standardının 2015 revizyonu risk temelli düşünme üzerine oturan bir kalite yönetim sistemi tarif etmektedir. Bu standardın şartlarını sağlamak için kuruluş, risk ve firsatları belirlemek amaciyla faaliyetleri planlaması ve uygulaması gerekir. Risk ve firsatların belirlenmesi, kalite yönetim sisteminin etkinliğinin arttırılması, iyileştirilmiş sonuçlara erişim ve olumsuz etkileri önlemek için bir temel oluşturur (28).

\section{Risk Yönetimi ve Sağlıkta Akreditasyon Standartları (SAS)}

Sağlıkta Akreditasyon Standartları Risk Yönetimi başlıklı bir bölüme sahiptir ve "Hastane ve hastanede sunulan hizmetlere ilişkin riskler yönetilmelidir." standardının altında bütüncül bir risk yönetim sürecine ilişkin değerlendirme ölçütleri belirlemiştir (29).

\section{Risk Yönetimi Uygulama Örneği}

\subsection{Risk Yönetimi Ekibinin Oluşturulması}

Risk Yönetimi Ekibi; Başhekim, Tıbbi Direktör, İdari Direktör, Hemşirelik Hizmetleri Müdürü, Akreditasyon Yöneticisi ve Komite Başkanlarından oluşmaktadır.

\subsection{Planlama ve Risklerin Belirlenmesi}

Sağlık Kurumu bünyesinde yürütülmekte olan Kalite Yönetim Sistemi kapsamı dahilinde stratejik planlamayı etkileyebilecek ilgili taraflar, ilgili tarafların beklenti, ihtiyaçları, iç ve dış faktörler, risk ve firsatlar üst yönetim ve birim yöneticilerinin katılımı ile gerçekleştirilen stratejik plan toplantılarında ve kalite toplantılarında belirlenir. Riskler ve firsatlar idari ve destek hizmet birimleri tarafından, birim liderleri sorumluluğunda, tanımlanmış süreçler dikkate alınarak belirlenir ve takip edilir. Ayrıca Risk Yönetimi Ekibi tarafından Risk Yönetim Planı hazırlanır ve İç tetkiklere dahil edilerek, sonuçları Yönetimin Gözden Geçirme Toplantıları için girdi olarak veri teşkil eder. Performans göstergelerinin sonuçları, uygunsuzluk yönetim sistemi ve güvenli raporlama sistemi ile tespit edilen riskler de risk yönetim planına dahil edilir.

\subsection{Risk Yönetimi Metodolojisi}

Tüm süreçlerde, önemi ne olursa olsun, risklerin açik olarak dikkate alınmasını ve uygun bir dereceye kadar risk yönetiminin uygulanmasını gerektirir. Uygulama tecrübelerinden çıkarımda bulunulur ve sürekli iyileștirme için bilgi alınır. Şartları değiştirmek yararlı oldu mu, riskler elemine edildi mi, en iyi zamanlama vb. değişikliklerden doğabilecek firsatların tespit edilmesi sağlanır.

Risklerin değerlendirmesinde ve takibinde tüm süreç ve kalite yöneticilerinin görüş ve değerlendirmelerine başvurulur.

Tehlikeler her bir süreç için ayrı değerlendirilir ve risk tanımlamaları yapılır. Mevcut risklerin birim bazında etkileri ayrı ayrı değerlendirilir ve puanlanır. 
Riskin Azaltılması; Riski yaratan sebebi ortadan kaldırmaktır.

Riskten Kaçınma; Uygulama düzeyinde riskin azaltılamadığ 1 ve risk kabul seviyesinin üzerinde olan riskler için riskten kaçınma seçeneği geçerlidir.

Riskin Kabulü/ Üstlenilmesi: Riskin var olduğunu kabul ederek faaliyetlere devam edilmesidir.

Riski diğer taraf veya taraflarla paylaşma: Riskin gerçekleşmesi durumunda oluşabilecek zararı karşılayacak çözümler bularak (örneğin sigorta yaptırmak) riskin aktarılmasıdır.

Azaltma seçeneği seçilmiş riskler için Risk Yönetim Planı'nda hedef ve sorumlular belirlenir.

\section{Tehlikelerin Tanımlanması}

Tehlikeler tanımlanırken çalışma ortamı, çalışanlar ve iş yerine ilişkin ilgisine göre asgari olarak aşağıda belirtilen bilgiler toplanır;

- Sağlık Kurumu tesisi ve eklentileri

- Sağllk Kurumunda yürütülen faaliyetler ile iş ve işlemler

- Hizmet süreci ve yöntemleri

- İş ekipmanları

- Kullanilan maddeler

- Artık ve atıklarla ilgili maddeler

- Organizasyon ve hiyerarşik yapı, görev, yetki ve sorumluluklar

- Çalışanların tecrübe ve düşünceleri

- İşe başlamadan önce ilgili mevzuat gereği alınacak çalışma izin belgeleri

- Çalışanların eğitim, yaş, cinsiyet vb. özellikleri ile sağlık gözetimi kayıtları

- Genç, yaşlı, engelli, gebe veya emziren çalışanlar gibi özellikli grupların durumu

- Gerçekleştirilmiş denetimlere ilişkin sonuçlar

- Meslek hastalığı kayıtları

- İş kazası kayıtları

- İşyerinde meydana gelen ancak yaralanma veya ölüme neden olmadığı halde iş yeri ya da iş ekipmanının zarara uğramasına yol açan olaylara ilişkin kayıtlar

- Ramak kala olay kayıtları
- Ürün güvenlik bilgi formları

- Ortam ve kişisel maruziyet düzeyi ölçüm sonuçları

- Varsa daha önce yapılmış risk değerlendirmesi çalışmaları

- Acil durum planları

- Vardiya düzeni

- Ekip çalışması

- Ziyaretçi veya işyeri çalışanı olmayan diğer kişiler

- Uygunsuzluk raporları

- Güvenli Raporlama Sistemi çıktıları

- Performans göstergeleri sonuçları

Bilgi toplama çalışmaları sırasında tüm birimlerden ve yöneticilerden görüş ve öneri alınır.

\section{Risk Analizi}

Tespit edilmiş olan tehlikelerin her biri ayrı ayrı dikkate alınarak bu tehlikeden kaynaklanabilecek bu risklerin hangi sıklıkta (olasılık) oluşabileceği ile bu risklerden kimlerin, nelerin, ne şekilde ve hangi şiddetle zarar göreceği belirlenir.

\section{Olasılığın hesaplanması}

Tehlikenin ortaya çıkma olasıllığı için Tablo 1'de belirtilen değerlerden biri saptanarak puanlama yapılır. Bu değerler özellikle kaza istatistikleri, ramak kala olay tutanakları, işyeri sağlık-güvenlik organizasyonu, işçilerin eğitim durumu, işyerinin iş sağllğı güvenliği uygulamaları göz önüne alınarak saptanır.

Tablo 1: Olasılık Değerlendirmesi

\begin{tabular}{|l|l|l|}
\hline \multicolumn{2}{|l|}{ OLASILIK } & \multirow{2}{*}{ AÇIKLAMA } \\
\cline { 1 - 2 } $\begin{array}{l}\text { NİCEL } \\
\text { DEĞERLER }\end{array}$ & NITEL DEĞERLER & \\
\hline 0,2 & Beklenmez & $\begin{array}{l}\text { Daha önce gerçekleştiği } \\
\text { bilinmeyen }\end{array}$ \\
\hline 0,5 & $\begin{array}{l}\text { Beklenmez fakat } \\
\text { mümkün }\end{array}$ & $\begin{array}{l}\text { Daha önce gerçekleştiği } \\
\text { bilinen }\end{array}$ \\
\hline 1 & $\begin{array}{l}\text { Mümkün fakat düşük } \\
\text { ihtimal }\end{array}$ & $\begin{array}{l}\text { İşyerinde daha önce } \\
\text { gerçekleşmiş }\end{array}$ \\
\hline 3 & Nadir fakat olabilir & $\begin{array}{l}\text { İşyerinde daha önce birkaç } \\
\text { kez gerçekleşmiş }\end{array}$ \\
\hline 6 & Yüksek & Yakın zamanda gerçekleşen \\
\hline 10 & Çok Kuvvetli & $\begin{array}{l}\text { Yakın zamanda işyerinde } \\
\text { gerçekleşen }\end{array}$ \\
\hline
\end{tabular}




\section{Sıklık Değerlendirmesi}

Tehlikenin gerçekleşme sıklığına göre Tablo2'de belirtilen değerlere göre sıklık puanlaması yapılır.

Tablo 2: S1klık Değerlendirmesi

\begin{tabular}{|l|l|l|}
\hline \multicolumn{2}{|l|}{ FREKANS/SIKLIK } & \multirow{2}{*}{ AÇIKLAMA } \\
\cline { 1 - 2 } NICEL DEĞERLER & NİTEL DEĞERLER & \\
\hline 0,5 & Çok Seyrek & Y1lda 1 veya daha az \\
\hline 1 & Seyrek & Yılda 1-2 kere \\
\hline 2 & Sik Değil & Ayda 1-2 kere \\
\hline 3 & Ara Sıra & Haftada 1-2 kere \\
\hline 6 & Siklıkla & Günde 1-2 kere \\
\hline 10 & Sürekli & Saatte birden fazla \\
\hline
\end{tabular}

\section{Şiddetin Hesaplanması}

Tehlikenin gerçekleşmesi durumunda şiddet değeri için Tablo 3'te belirtilen değerlerden biri saptanır. Daha önce meydana geldiği bilinen bir olayın analizinde puanlama olay sonucu göz önünde bulundurularak yapılır.

Tablo 3: Şiddetin Hesaplanması

\begin{tabular}{|l|l|l|}
\hline \multicolumn{2}{|l|}{ ŞiDDET } & \multirow{2}{*}{ AÇIKLAMA } \\
\cline { 1 - 2 } $\begin{array}{l}\text { NICEL } \\
\text { DEĞERLER }\end{array}$ & NITTEL DEĞERLER & \\
\hline 1 & Dikkate Alınması Gerekli & $\begin{array}{l}\text { Ramak kala, hafif, } \\
\text { zararsız }\end{array}$ \\
\hline 3 & Önemli & $\begin{array}{l}\text { Küçük hasar, düşük iş } \\
\text { kaybı, ilkyardım }\end{array}$ \\
\hline 7 & Ciddi & $\begin{array}{l}\text { Önemli zarar, dış tedavi, } \\
10 \text { güne kadar iş kayb1 }\end{array}$ \\
\hline 15 & Çok Ciddi & $\begin{array}{l}\text { Sakatlık, uzuv kayb1, dış } \\
\text { tedavi, 10 günü kadar iş } \\
\text { kayb1 }\end{array}$ \\
\hline 40 & Çok Kötü & $\begin{array}{l}\text { Ölüm, tam maluliyet, } \\
\text { ağır çevre hasarı }\end{array}$ \\
\hline 100 & Felaket & $\begin{array}{l}\text { Birden çok ölüm, önemli } \\
\text { çevre felaketi }\end{array}$ \\
\hline
\end{tabular}

\section{Olasılık, Frekans ve Şiddet Değerlerini Kullanarak Risk Değerinin Belirlenmesi}

Risk puanı, olasılık, frekans ve şiddet değerlerinin çarpılması ile elde edilerek, Tablo 4'te verilen "Risk Puanı Belirleme Matrisine" yerleştirilir.
Tablo 4: Risk Puanı Belirleme Matrisi

\begin{tabular}{|c|c|c|}
\hline $\begin{array}{l}\text { RİSK } \\
\text { DEĞERİ }\end{array}$ & RİSK DEĞERLENDİRME SONUCU & $\begin{array}{l}\text { TAKİP } \\
\text { SIKLIĞI }\end{array}$ \\
\hline $400<\mathrm{R}$ & $\begin{array}{l}\text { Çok yüksek risk, } \\
\text { Hemen gerekli önlemler alınmalı veya tesis, } \\
\text { bina, çevrenin kapatılması düşünülmelidir. }\end{array}$ & Haftalık \\
\hline $200<\mathrm{R}<400$ & $\begin{array}{l}\text { Yüksek risk, } \\
\text { Kısa dönemde iyileştirilmelidir, yeni benzer } \\
\text { faaliyet başlamamalıdır. } \\
\text { (aylık eylem planı içerisinde) }\end{array}$ & Aylık \\
\hline $70<\mathrm{R}<200$ & $\begin{array}{l}\text { Önemli risk, } \\
\text { Eylem planına alınmalı, iyileştirilmelidir ve } \\
\text { gözetim altında uygulanmalıdır (yıl içinde) }\end{array}$ & 3 Aylik \\
\hline $20<\mathrm{R}<70$ & $\begin{array}{l}\text { Olası risk, } \\
\text { Eylem planına alınmalıdır, }\end{array}$ & 6 Aylık \\
\hline $\mathrm{R}<20$ & $\begin{array}{l}\text { Kabul edilebilir risk, } \\
\text { Önlem öncellikli değildir }\end{array}$ & Y1llik \\
\hline
\end{tabular}

\section{Alınacak Önlemlere Karar Verilmesi ve Aksiyon Planı}

Yerleştirme sonucunda risk Tablo 4'teki sıralamaya uygun olarak değerlendirilir. Analiz edilen riskler, kontrol tedbirlerine karar verilmek üzere etkilerinin büyüklügüne ve önlemlerine göre en yüksek risk seviyesine sahip olandan başlanarak öncelik sıralaması yapılır ve Risk Yönetim Planı'na işlenir. Riskin tamamen bertaraf edilmesi, eğer mümkün değil ise riskin kabul edilebilir seviyeye indirilmesi için aşağıdaki adımlar uygulanır:

- Tehlike veya tehlike kaynaklarının ortadan kaldırılması

- Tehlikelinin, tehlikeli olmayanla veya daha az tehlikeli olanla değiştirilmesi

- Riskler ile kaynağında mücadele edilmesi

Karşıllaştırılan tedbirlerin iş ve işlem basamakları, işlemi yapacak kişi ya da işyeri bölümü, sorumlu kişi ya da işyeri bölümü, başlama ve bitiş tarihi ile benzeri bilgileri içeren bilgiler Risk Yönetim Planına işlenir.

\section{Risklerin Etkinlik Değerlendirmesi}

Hazırlanan planların uygulama adımları düzenli olarak izlenir, denetlenir ve aksayan yönler tespit edilerek gerekli düzenleyici ve önleyici işlemler tamamlanır. Belirlenen risk için kontrol tedbirlerinin hayata geçirilmesinden sonra yeniden risk puanı tespiti ve Risk Yönetim Planına işlenir. Risk olmaktan çıkmış olan durumlar Risk Yönetim Planından çıkartılır. Daha önce var olmayan ancak değerlendirilen periyotta ortaya çıan riskler plana eklenir. Risk Yönetim 
Planı yaşanan olaylarla ve yapılan kontrollerle sürekli güncellenen bir doküman niteliğindedir.

Aşağıda belirtilen durumlardan ortaya çıkabilecek yeni risklerin, iş yerinin tamamını veya bir bölümünü etkiliyor olması göz önünde bulundurularak risk değerlendirilmesi tamamen veya kısmen yenilenir:

- İşyerinin taşınması veya binalarda değişiklik yapılması

- İşyerinde uygulanan teknoloji, kullanılan madde ve ekipmanlarda değişiklikler meydana gelmesi

- Çalışma yönteminde değişiklikler olması

- İş kazası, meslek hastalığı veya ramak kala olay meydana gelmesi

- Çalışma ortamına ait sınır değerlere ilişkin bir mevzuat değişikliği olması

- Çalışma ortamı ölçümü ve sağlık gözetim sonuçlarına göre gerekli görülmesi

- İşyeri dışında kaynaklanan ve işyerini etkileyebilecek yeni bir tehlikenin ortaya çıkması
- Yeni bir tehlike tespit edildiğinde veya ortaya çıktığında

Risk Yönetim Planı Şablonu Tablo 5’te gösterilmiştir.

\section{TARTIŞMA}

Tüm işletmeler gibi sağlı kurumları da karşılaştığı risklerin farkında olarak olası zararların bertaraf edilmesi ya da azaltılması, risklerin firsata dönüştürülmesi için faaliyetler planlamalıdır. Her kurumun durumu, koşulları, kaynakları, çevresi farklı olduğundan karşılaşacağı riskler ve bu risklerin etkileri de farklıdır bu nedenle kurumların kendilerini ve çevrelerini iyi tanımaları önemlidir. Kurumlar risklerini bütüncül bir bakış açısıyla ve tüm çalışanları sürecin içine katarak yönetmelidir. Risk yönetiminde bu çalışmada şablonu sunulmuş olan Risk Yönetim Planları önemli bir araç olarak rol oynar, bu planlar sürekli yaşayan ve güncelliğini koruyan dokümanlar olduğu sürece faydalıdırlar. Bu sürecin başarısı tüm tarafları birleştirici özelliği olan risk yöneticisi pozisyonundaki kişinin doğru seçilmesi ile mümkün olacaktır.

Tablo 5: Risk Yönetim Planı Şablonu

\begin{tabular}{|c|c|c|c|c|c|c|c|c|c|c|c|c|c|}
\hline \multirow[b]{2}{*}{ 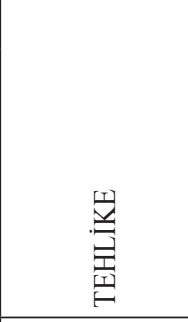 } & \multirow[b]{2}{*}{ 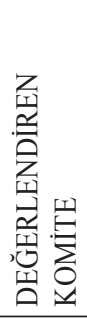 } & \multirow[b]{2}{*}{$\frac{v}{\sim}$} & \multirow[b]{2}{*}{ 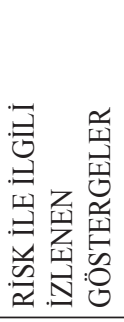 } & \multirow[b]{2}{*}{ 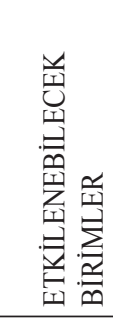 } & \multicolumn{5}{|c|}{ RİSK DEĞERLENDİRME } & \multirow[b]{2}{*}{$\begin{array}{l}\text { ALINMASI } \\
\text { GEREKEN } \\
\text { ÖNLEMLER, } \\
\text { ÖNERILER, } \\
\text { AKSIYONLAR, } \\
\text { DÖFLER }\end{array}$} & \multicolumn{3}{|c|}{ AKSIYON PLANI } \\
\hline & & & & & 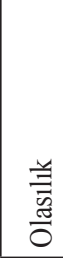 & 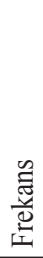 & $\frac{\overrightarrow{0}}{\overline{0}}$ & 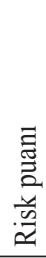 & 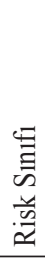 & & 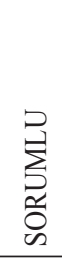 & : & 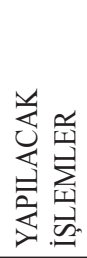 \\
\hline $\begin{array}{l}\text { Kullanılan } \\
\text { cihazların } \\
\text { güvenliğinin } \\
\text { sağlanamaması }\end{array}$ & & $\begin{array}{l}\text { 1. Hatalı teşhis } \\
\text { konması } \\
\text { 2. Hastanın ve } \\
\text { çalışanın zarar } \\
\text { görmesi } \\
\text { 3. Yangın ve } \\
\text { elektrik güvenliği } \\
\text { ile ilgili kazaların, } \\
\text { acil durumların } \\
\text { ortaya çıkması } \\
\text { 4. Tedavi } \\
\text { kalitesinin düşmesi } \\
\text { 5. Enfeksiyon } \\
\text { oluşması } \\
\text { 6. Radyasyon Riski }\end{array}$ & & $\begin{array}{l}\text { Tüm } \\
\text { birimler }\end{array}$ & & & & & & & & & \\
\hline
\end{tabular}




\section{KAYNAKLAR}

1. International Standardization of Organization, ISO 31000 , 2009

2. Singh B, Ghatala M H; Risk Management in Hospitals, International Journal of Innovation, Management and Technology, Vol.3,No.4, August 2012

3. Carroll R L, Risk Management Handbook for Health Care Organizations, 3 Volume Set, 2011, American Society for Healthcare Risk Management

4. American Society For Healthcare Risk Management, Enterprise Risk Management Part Two: Getting an ERM program started, 2006

5. http://www.saglikplatformu.com/saglik_egitimi/ showquestion.asp?faq $=6 \&$ fldAuto $=231$, Erişim tarihi: 2 Ocak 2018

6. Scordis N A, Connecting ERM, Strategic Risk Management and Sustainability, 2012

7. American Society For Healthcare Risk Management, Enterprise Risk Management Part Two: Getting an ERM program started, 2006

8. (https://elearning.scranton.edu/resource/business-leadership/ purpose-of-risk-management-in-healthcare, Erişim tarihi: 9 Ocak 2018

9. http://www.saglikplatformu.com/saglik_egitimi/ showquestion.asp?faq $=6 \&$ fldAuto $=231$, Erişim tarihi: 2 Ocak 2018

10. American Society For Healthcare Risk Management, Enterprise Risk Management Part Two: Getting an ERM program started, 2006

11. Singh B, Ghatala M H; Risk Management in Hospitals, International Journal of Innovation, Management and Technology, Vol.3,No.4, August 2012

12. Dionne G, Risk Management: History, Definition, and Critique, Risk Management and Insurance Review, 2013, Vol.16, No.2, 147-166

13. American Society For Healthcare Risk Management, Enterprise Risk Management Part Three: The role of the chief risk officer (CRO)

14. American Society For Healthcare Risk Management, Enterprise Risk Management Part Two: Getting an ERM program started, 2006
15. American Society For Healthcare Risk Management, Monograph, Enterprise Risk Management Part One: Defining The Concept, Recognizing Its Value, 2006 a

16. American Society For Healthcare Risk Management, Enterprise Risk Management Part Three: The role of the chief risk officer (CRO)

17. American Society For Healthcare Risk Management, Enterprise Risk Management: A Framework For Success, 2014

18. American Society For Healthcare Risk Management, Healthcare Risk Management: The Path Forward, 2014

19. American Society For Healthcare Risk Management, Enterprise Risk Management Part Two: Getting an ERM program started, 2006

20. http://www.saglikplatformu.com/saglik_egitimi/ showquestion.asp? faq $=6 \&$ fldAuto $=231$, Erişim tarihi: 2 Ocak 2018

21. American Society For Healthcare Risk Management, Monograph,Tackling Patient Safety Taxonomy: A Must For Risk Managers, 2008

22. Singh B, Ghatala M H; Risk Management in Hospitals, International Journal of Innovation, Management and Technology, Vol.3,No.4, August 2012

23. Aksay K, Orhan F, Kurutkan MN. Sağlık Hizmetlerinde Bir Risk Yönetimi Tekniği Olarak FMEA: Laboratuvar Sürecine Yönelik Bir Uygulama. Sağlıkta Performans ve Kalite Dergisi, 121-142, 2012.

24. International Standardization of Organization, ISO 31000 , 2009

25. International Standardization of Organization, A Practical Guide for SMEs ISO 31000 Risk Management, 2015

26. (https://www.iso.org/iso-31000-risk-management.html Erişim tarihi: 9.1.2018)

27. Joint Commission International, Joint Commission International Hastaneler İçin Akreditasyon Standartları, Beşinci Edisyon, 2014

28. International Standardization of Organization , ISO 9001, 2015

29. Sağlıkta Kalite ve Akreditasyon Daire Başkanlığı, Sağlıkta Akreditasyon Standartları Hastane Seti - v1.1/2015 